\title{
Three-Axis Accelerometer Package for Slimhole and Microhole Seismic Monitoring and Surveys
}

\author{
S.L. Hunter \\ P.E. Harben
}

January 7, 1997

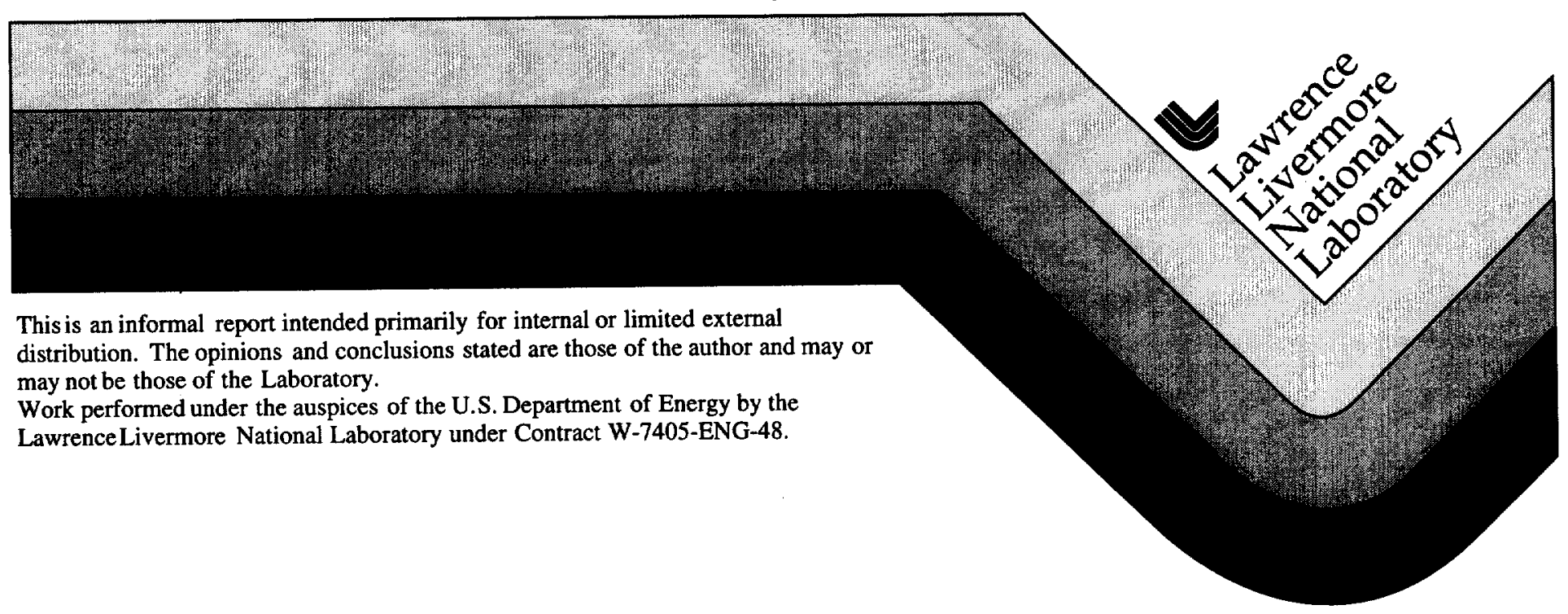




\section{DISCI.AIMER}

This document was prepared as an acoount of work sponsored by an agency of the United States Government. Neither the United States Government nor the University of California nor any of their employees, makes any warranty, express or implied, or assumes any legal liability or responsibility for the accuracy, completeness, or usefulness of any information, apparatus, product, or process disclosed, or represents that its use would not infringe privately owned rights. Reference herein to any specific commercial product, process, or service by trade name, trademark, manufacturer, or otherwise, does not necessarily constitute or imply its endorsement, recommendation, or favoring by the United States Government or the University of California. The views and opinions of authors expresed herein do not necesearily state or reflect those of the United States Government or the University of Callfornia, and shall not be used for advertising or product endorsement purposes.

This report has been reproduced directly from the best avallable copy.

Available to DOE and DOE contractors from the Office of Scientific and Technical Information

P.O. Box 62, Oak Ridge, TN 37831

Prices available from (615) 576-8401, FTS 626-8401

Available to the public from the

National Technical Information Service

U.S. Department of Commerce

5285 Port Royal Rd.,

Springfield, VA 22161 
Three-Axis Accelerometer Package for Slimhole and Microhole Seismic Monitoring and Surveys

\author{
S. L. Hunter \\ P. E. Harben
}

January 7, 1997 


\title{
Three-Axis Accelerometer Package for Slimhole and Microhole Seismic Monitoring and Surveys
}

\author{
S. L. Hunter and P. E. Harben
}

\begin{abstract}
The development of microdrilling technology, nominally defined as drilling technology for 1-in.-diameter boreholes, shows potential for reducing the cost of drilling monitoring wells. A major question that arises in drilling microholes is if downhole logging and monitoring in general-and downhole seismic surveying in particular-can be conducted in such small holes since the inner working diameter of such a seismic tool could be as small as $0.31 \mathrm{in}$.

A downhole three-component accelerometer package that fits within a 0.31 -in. inner diameter tube has been designed, built, and tested. The package consists of three orthogonally mounted Entran EGA-125-5g piezoresistive silicon micromachined accelerometers with temperature compensation circuitry, downhole amplification, and line drivers mounted in a thin-walled aluminum tube. Accelerometers are commercially available in much smaller package sizes than conventional geophones, but the noise floor is significantly higher than that for the geophones.

Cross-well tests using small explosives showed good signal-to-noise ratio in the recorded waveform at various receiver depths with a 150-ft source-receiver well separation. For some active downhole surveys, the accelerometer unit would clearly be adequate. It can be reasonably assumed, however, that for less energetic sources and for greater well separations, the high accelerometer noise floor is not acceptable. By expanding the inner working diameter of a microhole seismic tool to 0.5 in., other commercial accelerometers can be used with substantially lower noise floors.

\section{Introduction}

Slimhole coiled-tubing drilling (CTD) is sometimes preferred over conventional rotary drilling. A major advantage is that CTD minimizes formation damage; however, it is not significantly less expensive than conventional drilling for the typical CTD diameters of 2 and 2.375 in. It seems natural to question if smaller CTD holes can be drilled and instrumented that would result in a substantial cost savings when compared to conventional drilling.
\end{abstract}


The concept of microhole drilling has been advanced and developed by Los Alamos National Laboratory [1] and the economics compared to conventional rotary drilling. Microholes are roughly defined as drill holes with a nominal outer diameter of 1 in. For a nominal 10,000-ft borehole, assuming average penetration rates of $30 \mathrm{ft} / \mathrm{hr}$ for the CTD microhole, the cost is about half that of conventional drilling. If the average CTD microhole penetration rate can be doubled to $60 \mathrm{ft} / \mathrm{hr}$, the cost can be about one-fourth that of conventional drilling.

Microholes show promise in reducing the cost of drilling monitoring boreholes. In particular, the drill rig and mud handling system can be much more compact than existing rotary drilling systems. Furthermore, the reclamation requirements and cuttings disposal would be minimized. Assuming such small holes can be drilled, we must determine if seismic monitoring packages can be developed that fit within the holes and that can be used for conventional crosshole and vertical seismic profiling (VSP) surveys.

A joint project, including Lawrence Livermore National Laboratory, Los Alamos National Laboratory, Mark Products Inc., and Amoco Corporation, was funded by the Department of Energy Natural Gas and Oil Technology Partnership: Borehole Seismic Forum to develop a prototype microhole seismic monitoring system. Los Alamos had the lead responsibility to design and develop the downhole pressure casing, clamping, and geophone package. Mark Products Inc. developed miniature geophones, and Lawrence Livermore National Laboratory had the responsibility to develop a three-component accelerometer package that would fit inside the Los Alamos pressure casing. Amoco Corporation supplied the borehole test site.

We have developed a three-axis accelerometer package that was designed to fit within the most stringent of the inner-diameter limitations of a microhole seismic package: $0.31 \mathrm{in}$. The package uses commercially available piezoresistive, silicon micromachined accelerometers and custom-designed driving electronics. To some extent, the sensitivity of the accelerometer was traded off against package size so the diameter specification could be met. However, a relatively minor increase in the inner-diameter specification (say, to $0.5 \mathrm{in}$.) will allow more sensitive commercially available accelerometers to be packaged. Furthermore, new microaccelerometer designs such as tunneling accelerometers show promise for increased sensitivity with a package size smaller than current microaccelerometers.

\section{Package Design}

The sensor package consists of three orthogonal Entran EGA-125-5 piezoresistive silicon micromachined accelerometers. Each accelerometer has a temperature-compensation module. Table 1 lists the sensor specifications. 
Table 1.

\begin{tabular}{ll}
\hline Range & $\pm 5 \mathrm{~g}$ \\
Sensitivity & $15 \mathrm{mV} / \mathrm{g}$ \\
Resonance frequency & $300 \mathrm{~Hz}$ \\
Nonlinearity & $\pm 1 \%$ \\
Thermal sensitivity & $\pm 2.5 \% / 100^{\circ} \mathrm{F}$ \\
Weight & $0.5 \mathrm{~g}$ \\
\hline
\end{tabular}

The sensor output is connected to a custom-designed, three-channel signal conditioning circuit board. This circuit board uses an instrumentation amplifier and a line driver for each channel. Figure 1 shows the circuit schematic for the three-channel amplification board.

The accelerometers, temperature-compensation modules, and amplification board can be potted inside a thin-walled aluminum tube or mounted inside the thick-walled stainless-steel sensor module section of the Los Alamos downhole tool. The tool provides clamping and a sealed environment for the sensor system. Figure 2 shows the entire assemblage.

\section{Seismic Monitoring with the Accelerometer Package}

A field test was accomplished at the Mounds Borehole Test Site, leased by the Amoco Corporation and located about 30 miles south of Tulsa, Oklahoma. The accelerometer package was mounted in a downhole pressure containment and clamping package built and supplied by Los Alamos National Laboratory. The clamping package used two independent spring-driven clamping arms, one located near the top and one near the bottom of the package.

The testing was conducted in a cemented steel pipe to emulate the coil tubing of a microhole. The unit was clamped at depths of 142,138 , and $58 \mathrm{ft}$ and was used to monitor nine explosive shots conducted in an adjacent well $150 \mathrm{ft}$ away and at a consistent depth of $135 \mathrm{ft}-2$ to $3 \mathrm{ft}$ below the water level in the shot hole. Table 2 lists the specifics of each shot. Data were recorded using a 16-bit Reftek data-acquisition unit operated at 1000 samples per second. This unit provided an effective recording bandwidth of 0 to $250 \mathrm{~Hz}$.

Figure 3 shows the signal for shot 8 . This record shows the signal recorded by one of the horizontal component accelerometers for the largest source-receiver distance and the smallest explosive charge. Clearly, the signal-to-noise ratio under the conditions of this shot is adequate enough to be useful in downhole seismic surveys. 
Table 2.

\begin{tabular}{lccl}
\hline $\begin{array}{c}\text { Shot } \\
\text { No. }\end{array}$ & $\begin{array}{c}\text { Recelver } \\
\text { depth }(t)\end{array}$ & $\begin{array}{c}\text { Explosive } \\
\text { charge }(g)\end{array}$ & Comments \\
\hline 1 & 142 & $8^{a}$ & Good signal \\
2 & 142 & 4 & Good signal \\
3 & 142 & 8 & Good signal \\
4 & 142 & 8 & Bad record \\
5 & 138 & 4 & Good signal \\
6 & 138 & 8 & Bad record \\
7 & 58 & 8 & Good signal \\
8 & 58 & 4 & Good signal \\
9 & 58 & 4 & Good signal \\
\hline
\end{tabular}

Although the field notebook indicates a 4-g shot, the data indicate $8 \mathrm{~g}$. Therefore, we assume in this report that the field record was in error.

The seismic tool was clamped and resting on the bottom of the receiver borehole for shots 1,2 , and 3 . These shots were fired under identical conditions with charges of 8,4 , and $8 \mathrm{~g}$, respectively. Records are shown in Figure 4 . The waveforms are similar but clearly not identical. The primary source of variability is attributed to slight differences in the conditions for each test shot (i.e., depth below water table and position within the borehole casing). Note the lower amplitude of the first arrival on the 4-g charge compared with the 8-g charges.

Figure 5 shows the spectra of the signal and background pre-event noise. The noise floor of the accelerometer is well above the background seismic noise [2] and is principally governed by the Brownian motion noise due to the extremely small suspended mass used in the unit [3]. The plots are seven-point smoothed acceleration amplitude spectra. Note that there is no measurable signal below about $30 \mathrm{~Hz}$. The peak signal amplitudes occur over a broad frequency range from about 120 to $220 \mathrm{~Hz}$. At $250 \mathrm{~Hz}$-the highfrequency limit of the recording system-the signal-to-noise ratio is still large, indicating that there is significant signal well above $250 \mathrm{~Hz}$.

The horizontal accelerometer component oriented parallel to the clamping axis is shown in Figures 3-5. This component appears to be better coupled to the formation than the component mounted perpendicular to the clamping axis. Figure 6 shows the two horizontal accelerometer components for shot 3 . Notice the significantly higher pre-event noise floor on the perpendicularly mounted component. The orientation of the downhole 
accelerometer horizontal components with respect to geographic coordinates was unknown but could be determined from the shot data.

\section{Potential Extensions and Applications}

The accelerometer package was designed to fit inside of the slightly larger pressure casing and clamping package supplied by Los Alamos. This outer casing would be critical for high-pressure applications and to allow the unit to be recoverable. The as-is package, however, can be used in lower pressure environments. Such a scenario will require that the unit be cemented into the borehole and sacrificed.

This particular accelerometer package could easily be adapted to form the sensor component of an air-deployed seismic monitoring system. Similar sensors are rated to survive a shock as large as $10,000 \mathrm{~g}$ 's, and the electronics can be internally potted within the confining tube using a material and method that has been demonstrated elsewhere [4]. An air drop system would, however, require the design of a radio transmitter module with power source or an internal digitizing and archiving module to complete the system.

\section{Conclusions}

An operational downhole three-component accelerometer package that fits within a 0.31 -in. inner diameter tube has been demonstrated. The primary problem with the small package size is that it limits the commercially available sensors that can be used to just a few choices with a relatively low sensitivity. Although the test results for this accelerometer package show utility in some potential cross-well surveys, it can reasonably be assumed that for large well separations or smaller source strengths, the accelerometer would prove inadequate because of the high noise floor of the units. It is not likely that microaccelerometers will approach the sensitivity of standard geophones, although new products will be much more sensitive than those that are currently available.

The accelerometer instrumentation does present some advantages over geophones. The accelerometers will operate in any orientation without any leveling concern. This can be important when operating in highly deviated directional drill holes where a geophone package would have to be gimbal mounted. Accelerometers can be made very rugged and are also useful for higher frequency recording, as may be desired in high-resolution cross-well imaging.

\section{Acknowledgments}

The effort described in this report is one task of the Microborehole Instrumentation project lead by Los Alamos National Laboratory and funded by the Department of Energy Natural Gas and Oil Technology Partnership: Borehole Seismic Forum. We are indebted 
to these organizations. In particular, we thank Jim Albright and Tom Fairbanks of Los Alamos National Laboratory for support and useful direction on this development effort and for supplying a downhole clamping package and field support during testing. We are also indebted to the Amoco Corporation for furnishing the Mounds Test Site and for field support during our field test.

\section{References}

[1] Thomson, J., and D. Dreesen, Microdrilling Economics and Feasibility, Las Alamos National Laboratory memorandum \#EES-4-94-50, March 14, 1994.

[2] Harben, P. E., and J. Lawson, Seismic Noise Variations in a 770-m-deep Borehole near Tulsa, Oklahoma, Lawrence Livermore National Laboratory, Livermore, CA, UCRL-LR-112429, 1992.

[3] Rodgers, P. W., "Frequency Limits for Seismometers as Determined from Signal-to-Noise Ratios. Part I, The Electromagnetic Seismometer," Bull. Seism. Soc. Am. 82(2), 1992.

[4] Hunter, S. L., and P. E. Harben, Air-Deployable Geophysics Package, Lawrence Livermore National Laboratory, Livermore, CA, UCRL-ID-115370, 1993. 


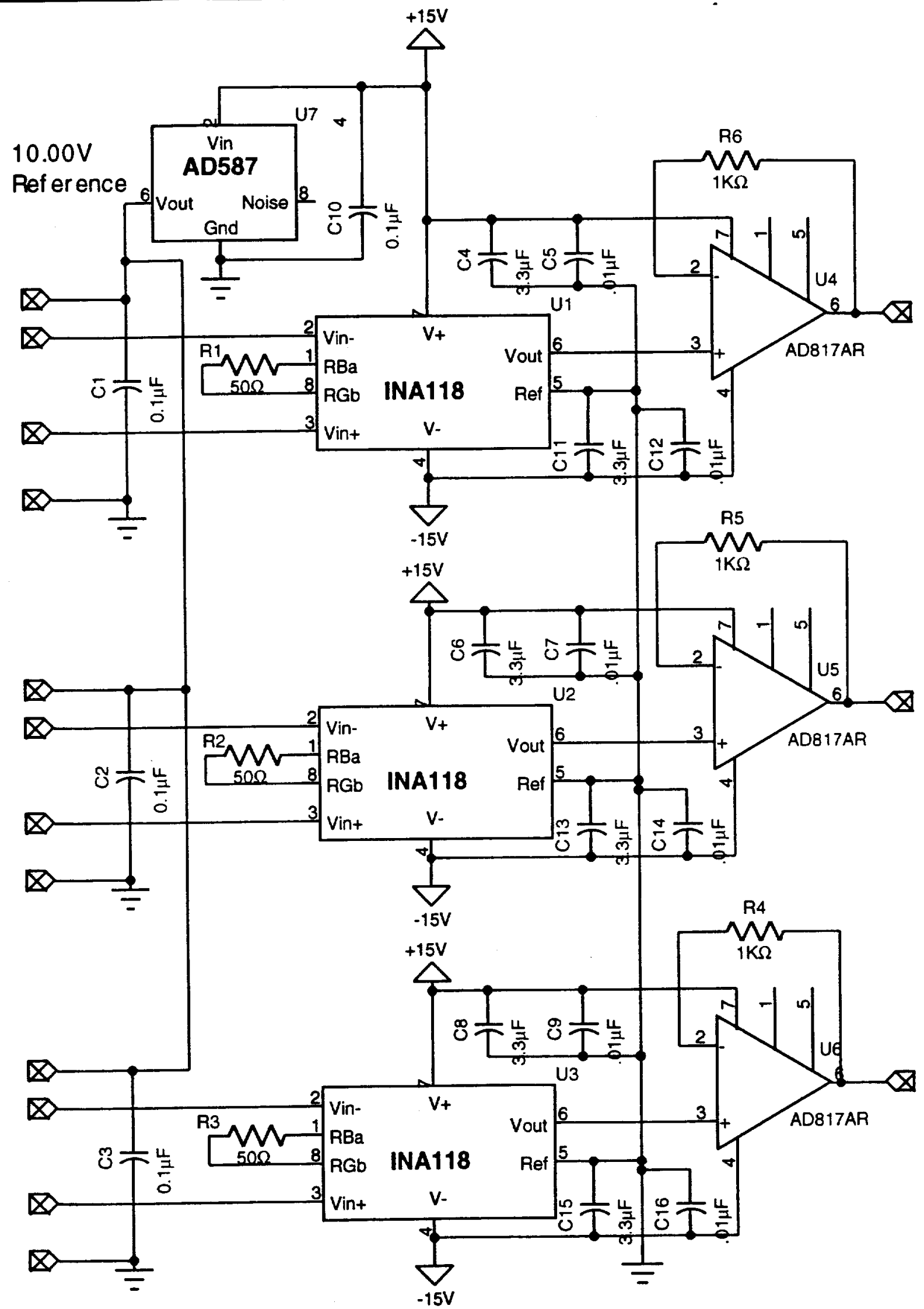

Figure 1. Schematic of the analog driving circuit for the three-channel accelerometer unit. 


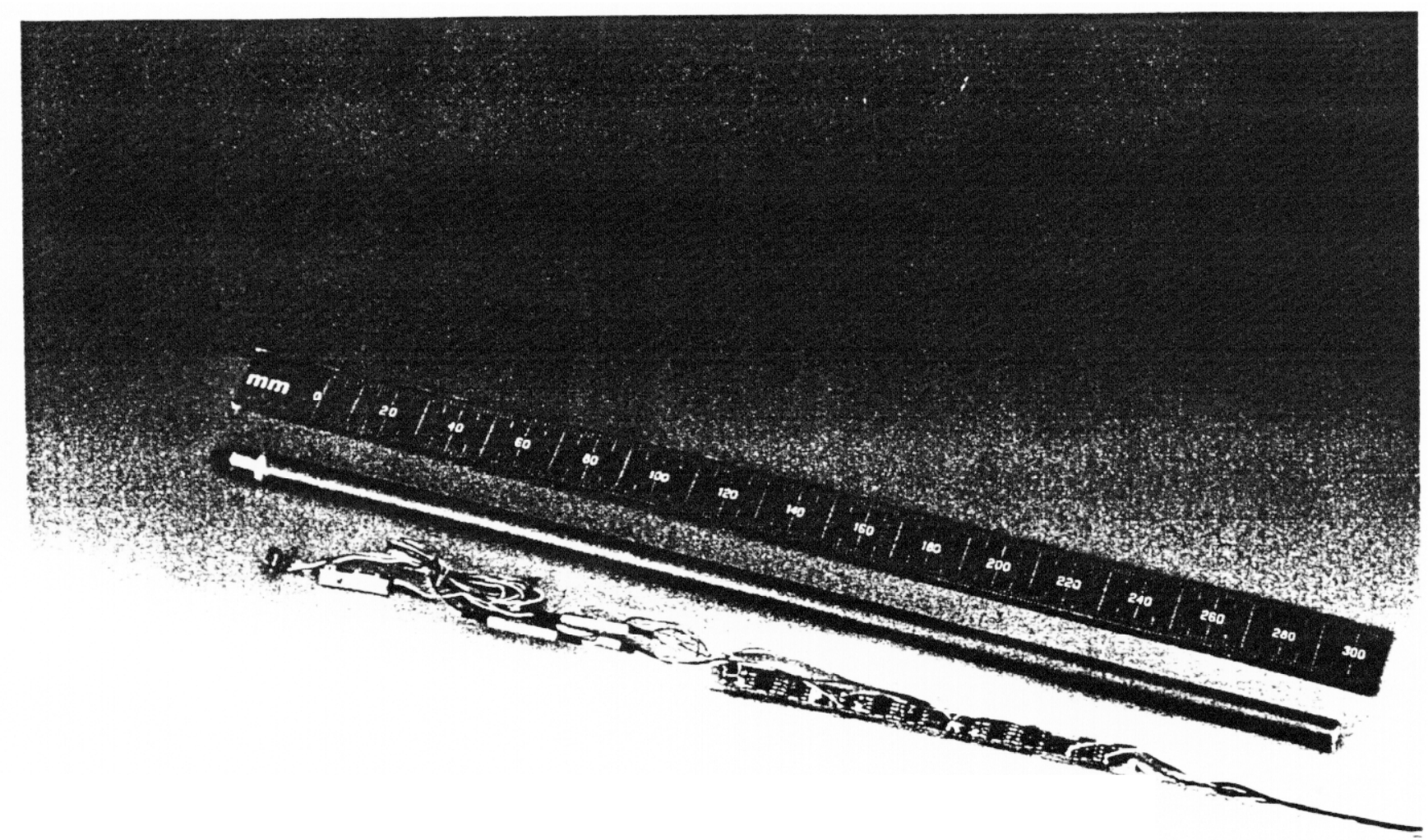

Figure 2. Photograph of the sensors, temperature compensation modules, and analog driving circuit board along with the aluminum tube the assemblage is mounted in. 


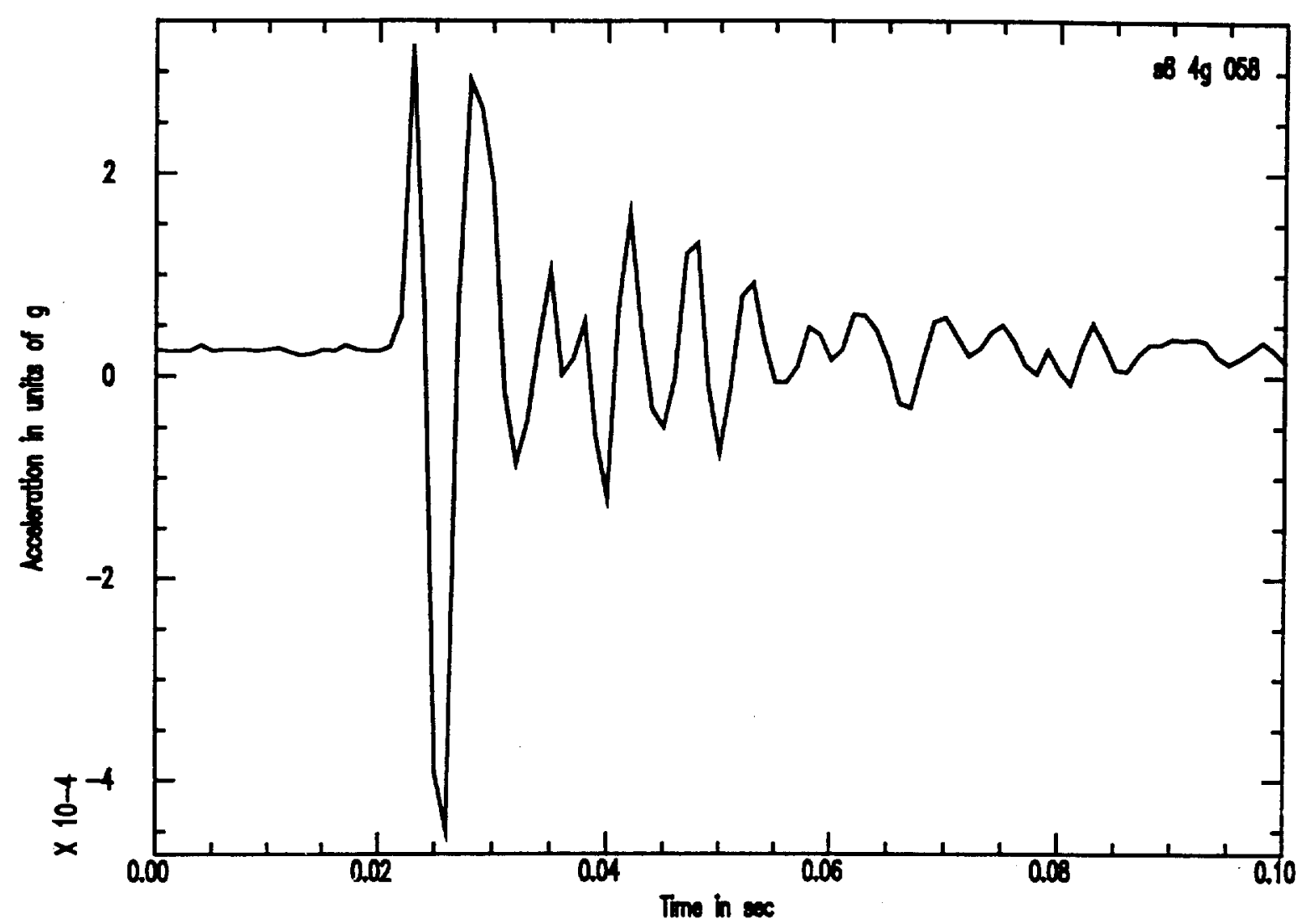

Figure 3. Horizontal component accelerometer recording along the clamping axis for shot 8 . 


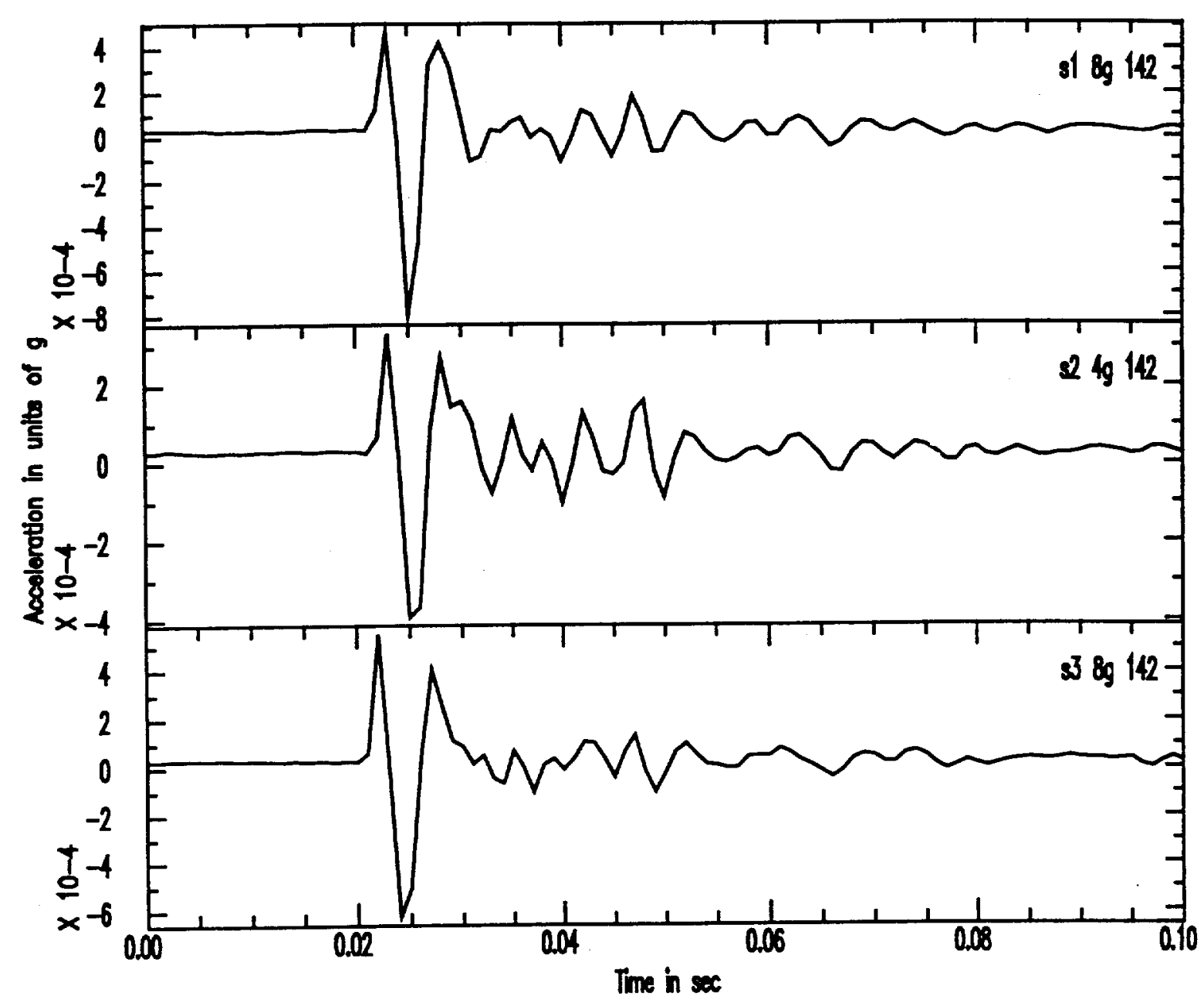

Figure 4. Repeated shots recorded by the horizontal component accelerometer along the clamping axis. Shots sizes were (top) $8 \mathrm{~g}$, (middle) $4 \mathrm{~g}$, and (bottom) $8 \mathrm{~g}$. 


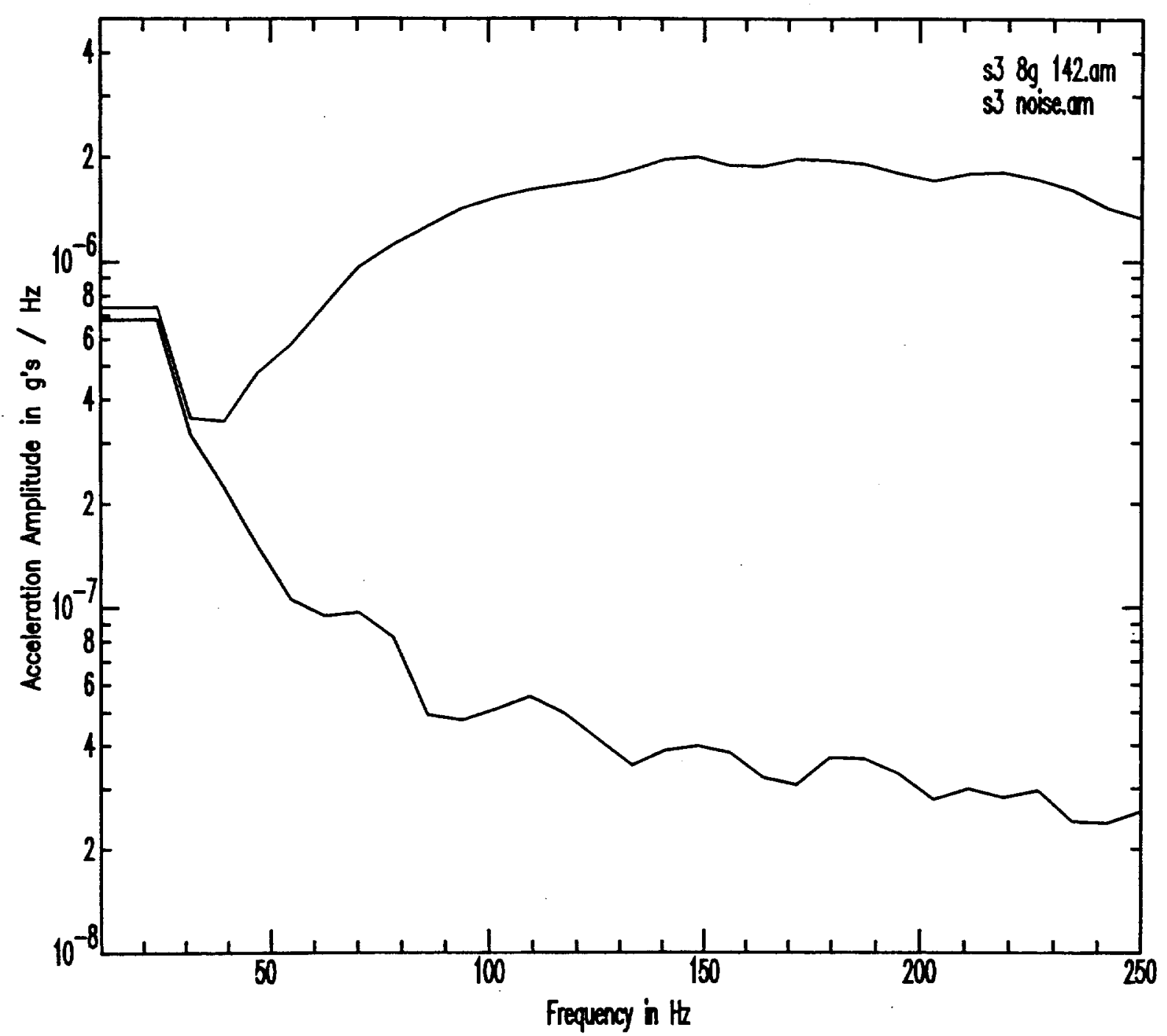

Figure 5. Smoothed amplitude spectra for the signal and pre-event noise for the horizontal component accelerometer along the clamping axis, shot 8 . 


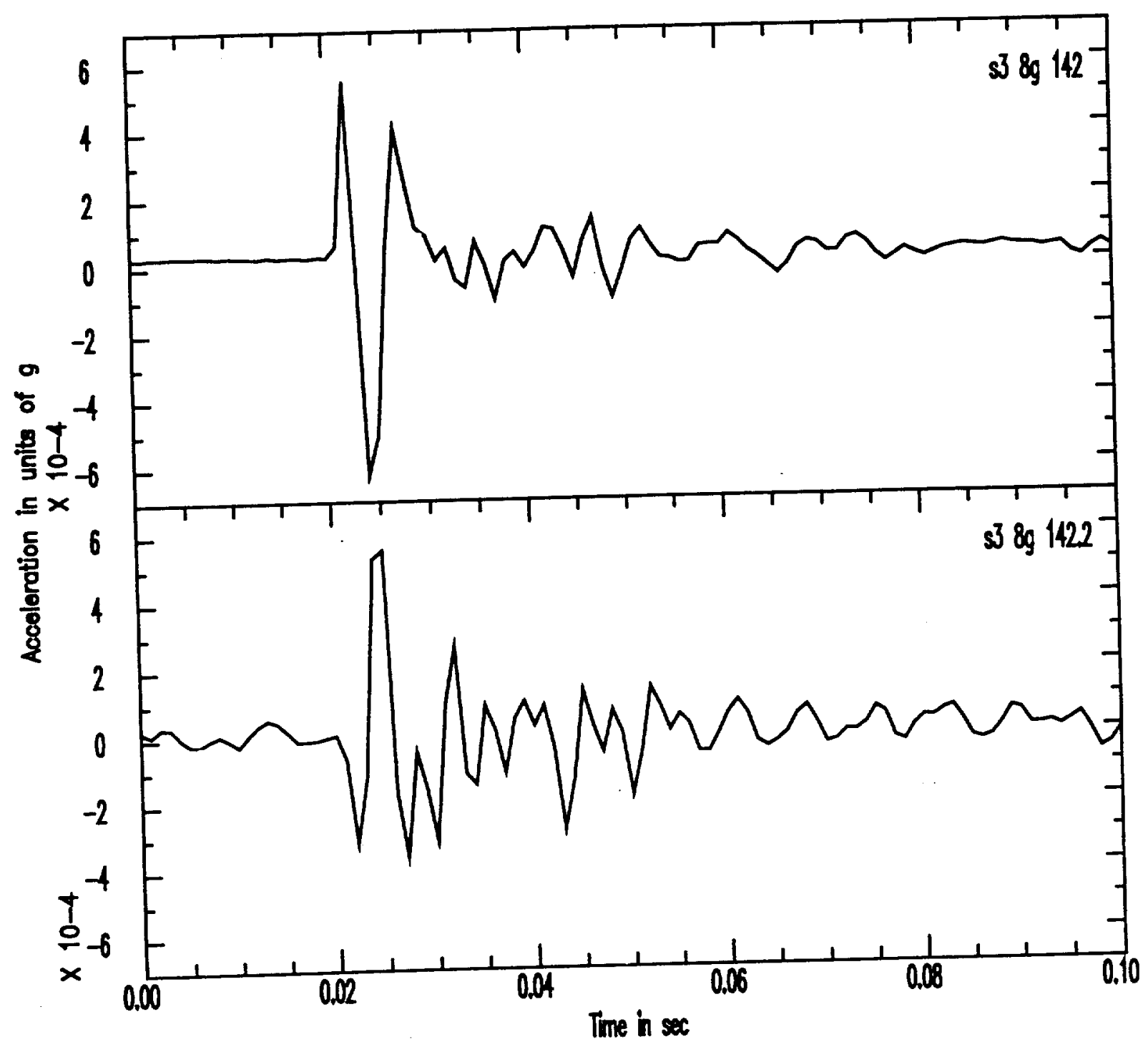

Figure 6. Horizontal accelerometer records for shot 6 . The top record is along the clamping axis, and the bottom record is perpendicular to the clamping axis. 


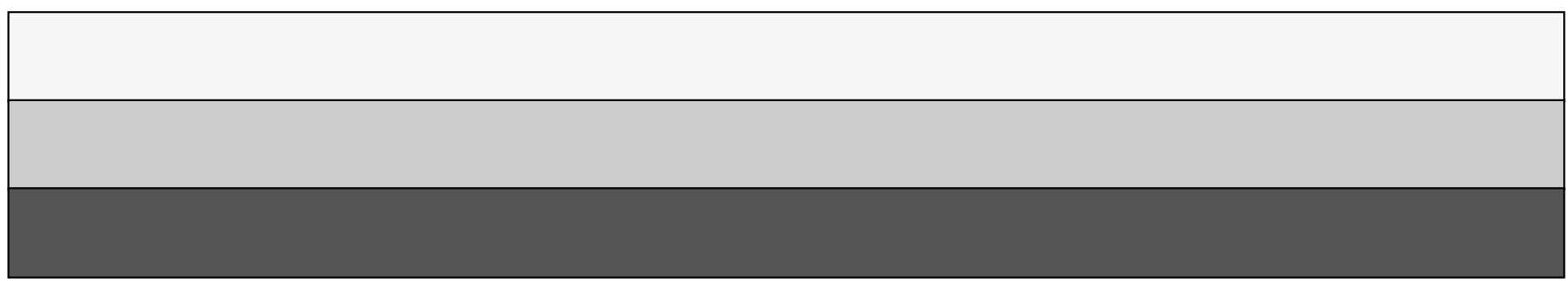

